\title{
Visual Loss after Cardiopulmonary Bypass (CABG) for Coronary Artery Disease: A Report of Case
}

\author{
Christos Simoglou, Fotios Konstantinou, Dimitrios Mikroulis, Savvas Elefteriadis, \\ Georgios Bougioukas
}

Department of Cardiothoracic Surgery, University Hospital of Evros, Democritous University of Thrace, Alexandroupolis, Greece

Email: simoglouchristosdoctor@yahoo.com

Received 30 November 2014; accepted 23 May 2015; published 26 May 2015

Copyright (C) 2015 by authors and Scientific Research Publishing Inc.

This work is licensed under the Creative Commons Attribution International License (CC BY).

http://creativecommons.org/licenses/by/4.0/

(c) $\underset{\mathrm{EY}}{0}$ Open Access

\begin{abstract}
We are reporting a 59-year-old male who presented with features of bilateral anterior ischaemic optic neuropathy after coronary artery bypass grafting. Postoperative vision loss after major nonocular surgery is a very rare but devastating complication since it has the potential to cause bilateral, severe and permanent loss of vision.
\end{abstract}

\section{Keywords}

\section{Cardiopulmonary Bypass, Visual Loss, Ophthalmological Test, Cross-Clamp, Extracorporeal Circulation}

\section{Introduction}

Visual loss is a rare $(0.0008 \%-0.002 \%)$ and destructive complication for patients undergoing cardiopulmonary bypass [1]. There is a big variety of factors that are implicated such as advanced age, diabetes, atherosclerosis, hyperlipidaemia, smoking, anaemia and diseases of the circulatory system. Futhermore, prolonged hypotension, prolonged time of extracorporeal circulation, intra-aortic balloon placement, vasospasm secondary to inotrops, transfusion of blood cells and even the use of amiodarone could lead to the same result for patients who underwent cardiopulmonary bypass [2]. All these factors, behavioring as majors or minors, advocate to ischaemic optic neuropathy or occlusion of the central retinal artery resulting to permanent loss of vision.

\section{Case Report}

A 59-year-old male was admitted to our clinic for an urgent operation because of a coronary artery disease. Co-

How to cite this paper: Simoglou, C., Konstantinou, F., Mikroulis, D., Elefteriadis, S. and Bougioukas, G. (2015) Visual Loss after Cardiopulmonary Bypass (CABG) for Coronary Artery Disease: A Report of Case. World Journal of Cardiovascular Surgery, 5, 45-48. http://dx.doi.org/10.4236/wjcs.2015.55008 
ronary angiography revealed a $90 \%$ stenosis of the left main stem artery, $85 \%$ stenosis of the proximal left anterior descending artery, $80 \%$ stenosis of the proximal ramus intermedius, total central occlusion of the circumflex artery and longitudal stenosis with total occlusion of the distal right coronary artery.

At the transthoracic echocardiography was found a mild regurgitation of the mitral and tricuspidal valves and overall satisfied contraction of the left ventricule. Unstable angina and loss of senses were the leading symptoms for his admission to the coronary unit 7 days before the operation. Formation of little atherosclerotic debrides on the carotid bulbs bilateral with hemodynamically not significant stenosis were confirmed on the echography control of the carotid arteries. Preoperatively, he was receiving medication for diabetes type II and hyperlipidaemia. The patient underwent double coronary bypass, while the duration of cardiopulmonary bypass was 131 minutes and the duration of cross-clamp time was 30 minutes. He was successfully weaned from CPB with a normal sinus rhythm. Hemodynamically stable (mean arterial pressure between 60 - $70 \mathrm{mmHg}$ ) under inotropic support (low doses of adrenaline i.v.) was transferred to the Cardiac intensive care and was extubated approximately seven hours after the end of the operation.

The first days after the operation there was a gradually increase of the administered doses of the adrenaline and additionaly noradrenaline is used, while the mean arterial pressure was not exceeding $60 \mathrm{mmHg}$. On the afternoon of the fourth day, the patient is complaining for blindness on the left eye and six hours later is suffering of complete visual loss. On the sebsequent ophtalmological test, a remarkable oedema and discoloration of the papilla bilateral was found. After wards, he was neurologically tested, a computer tomography and magnetic resonance as well was submitted. There were not found any evidences that could have caused this ominous complication. Finally, he was treated with methylprednisolone $1 \mathrm{gr}$ intravenous for three continuous days with no retrieval at his clinical status.

Ophthalmic examination had shown: VA counting fingers 5 meters OD, 6/6 vision OS, he had right pupillary defect, normal lens and IOP in both eyes, fundoscopy showed swollen optic disc in right eye, and small crowded disc left fundus. There were no cotton wool spots or emboli in either retinas. Vsual field of right eye was constricted with altitudinal defect. Fluorescein angiography was performed and it showed hypo-perfusion in right optic disc in choroidal phase. Venous phase showed leakage in the lower part of optic disc (Figure 1), and normal left optic disc (Figure 2), diagnosis of non-arteritric anterior ischemic optic neuropathy was established.

\section{Discussion}

Postoperative vision loss (POVL) after anesthesia is a rare. After cardiac surgery, patients may complain about transient loss of vision, poor reading ability and altered perception of color [3]. Some of these symptoms are transient, but in other cases visual loss may occur [4] [5].

Anterior ischaemic optic neuropathy is a relatively common cause of severe visual loss in middle age and elderly patients. The basic lesion is a segmental or generalized infarction within the prelaminar or laminar portion of the optic nerve, caused by occlusion of the short posterior ciliary arteries [6] [7].

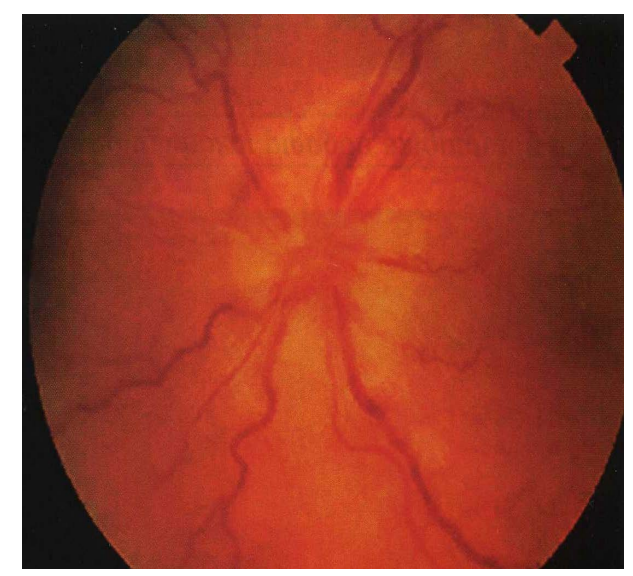

Figure 1. Venous phase fluorescein angiogram of the right eye showing leakage in the lower part of the optic disc. 


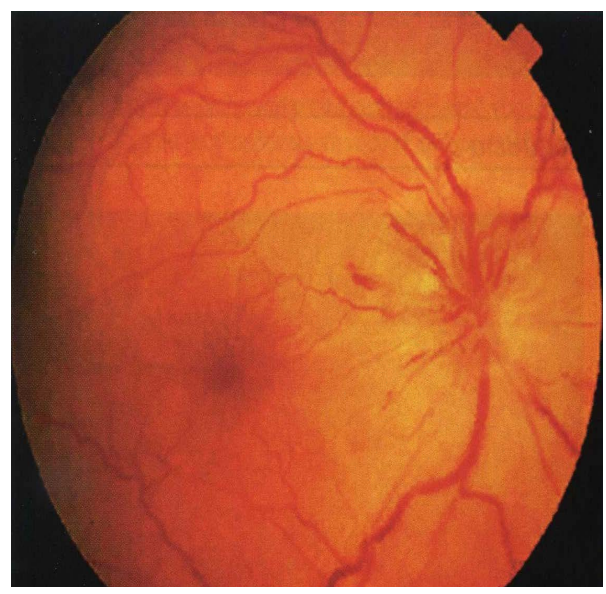

Figure 2. Arterio-venous phase fluorescein angiogram of the (normal vision) left eye.

Causes include atherosclerosis, giant cell arteritis (arteritic type anterior ischemic optic neuropathy), collagen vascular diseases, emboli, papilloedema and malignant hypertension. A few cases had been reported following coronary artery bypass surgery [8] [9].

We presented a report of case of anterior ischemic optic neuropathy (AION) following coronary bypass (CABG) surgery.

\section{Conclusions}

This case report is presented due to its rareness and leads us to a controversial dilemma. Patients should be informed preoperatively for the likelihood of permanent visual loss after the surgery.

We presented a report of case of anterior ischaemic optic neuropathy (AION) following coronary bypass (CABG) surgery.

Anterior ischemic optic neuropathy is a relatively common cause of severe visual loss in middle age and elderly patients. The basic lesion is a segmental or generalized infarction within the prelaminar or laminar plortion of the optic nerve caused by occlusion of the short posterior ciliary arteries. Causes include atherosclerosis, giant cell arteritis (arteritic type anterior ischemic optic neuropathy), collagen vascular diseases, emboli, papilloedema, and malignant hyperternsilon.

\section{Conflicts of Interest}

We would like to state that:

1) The material has not been previously published or submitted elsewhere for publication.

2) There are not conflicts of interest of any of the authors.

\section{References}

[1] Trethowan, B.A., Gilliland, H., Popov, A.F., Varadarajan, B., Phillips, S.-A., McWhirter, L. and Ghent, R. (2011) A Case Report and Brief Review of the Literature on Bilateral Retinal Infarction Following Cardiopulmonary Bypass for Coronary Artery Bypass Grafting. Journal of Cardiothoracic Surgery, 6, 154-155. http://dx.doi.org/10.1186/1749-8090-6-154

[2] Wernovsky, G., Mayer, J.E., Jonas, R.A., Hanley, F.L., Blackstone, E.H., Kirklin, J.W. and Castaneda, A.R. (1995) Factors Influencing Early and Late Outcome of the Arterial Switch Operation for Transposition of the Great Arteries. Journal of Thoracic and Cardiovascular Surgery, 109, 289-302. http://dx.doi.org/10.1016/S0022-5223(95)70391-8

[3] Roth, S. and Roizen, M. (1996) Optic Nerve Injury: Role of the Anesthesiologist. Anesthesia \& Analgesia, 82, 426439.

[4] Guyton, A.C. and Hall, J.E. (2000) Textbook of Medical Physiology. WB Saunders Co., Philadelphia, 595-597.

[5] Lee, L.A., Roth, S., Posner, K.L., Cheney, F.W., Caplan, R.A. and Newman, N.J. (2006) The American Society of Anesthesiologists Postoperative Visual Loss Registry: Analysis of 93 Spine Surgery Cases with Postoperative Visual 
Loss. Anesthesiology, 105, 652-659. http://dx.doi.org/10.1097/00000542-200610000-00007

[6] Moster, M.L. (1998) Visual Loss after Coronary Artery Bypass Surgery. Survey of Ophthalmology, 42, 453-457. http://dx.doi.org/10.1016/S0039-6257(97)00137-9

[7] Kline, R.A. (1994) Beneficial Effects of Hemodilution on Cerebral Microcirculation. Journal of Neurosurgical Anesthesiology, 6, 54-58. http://dx.doi.org/10.1097/00008506-199401000-00011

[8] Barner, H.B. (2008) Operative Treatment of Coronary Atherosclerosis. Annals of Thoracic Surgery, 85, $1473-1482$. http://dx.doi.org/10.1016/j.athoracsur.2008.01.014

[9] Mauri, L., Hsieh, W.H., Massaro, J.M., Ho, K.K., D’Agostino, R. and Cutlip, D.E. (2007) Stent Thrombosis in Randomized Clinical Trials of Drug-Eluting Stents. New England Journal of Medicine, 356, 1020-1029.

http://dx.doi.org/10.1056/NEJMoa067731 